\title{
O CONCEITO DE INTERESSE PÚBLICO NO ESTADO CONSTITUCIONAL DE DIREITO'
}

\author{
José Sérgio da Silva Cristóvam²
}

Resumo: $O$ estudo aborda os contornos do conceito de interesse público no Estado constitucional de direito, sob o marco da teoria do neoconstitucionalismo, com a crítica aos tradicionais contornos do princípio da supremacia do interesse público sobre o privado. O Estado constitucional de direito, assentado na teoria dos direitos fundamentais e na centralidade do princípio da dignidade da pessoa humana, reclama uma profunda redefinição dos contornos do regime jurídico administrativo, impondo-se a construção de um conceito de inte-

10 presente ensaio traz, de forma ainda preliminar e sintetizada (sem quaisquer pretensões exaurientes e sim uma análise panorâmica), as primeiras linhas da investigação desenvolvida pelo autor, junto ao Curso de Doutorado do Programa de Pós-Graduação em Direito da UFSC (PPGD/UFSC), sob a orientação do Prof. Dr. Ubaldo Cesar Balthazar, cuja temática central gravita em torno da "supremacia do interesse público no Estado constitucional de direito".

2 Doutorando em Direito Administrativo pela UFSC. Mestre em Direito Constitucional pela UFSC. Especialista em Direito Administrativo pelo CESUSC. Professor de Direito Administrativo da Escola Superior da Magistratura do Estado de Santa Catarina (ESMESC). Professor de Direito Administrativo da Escola Nacional de Administração (ENA/Brasil), em convênio com a École Nationale d'Administration (l'ENA/França). Professor de Direito Constitucional e Direito Administrativo da Escola Superior da Advocacia da OAB/SC (ESA-OAB/SC). Professor Titular de Ciência Política e Teoria Geral do Estado e Professor Substituto de Direito Administrativo no Curso de Graduação em Direito da UNIDAVI, bem como em Cursos de Pós-Graduação em Direito da UNIDAVI, CESUSC, UNISUL, UNOESC, Estácio de Sá, UnC e diversas outras instituições. Professor em cursos preparatórios para Concursos Públicos e Exames de Ordem, nas disciplinas de Direito Constitucional e Direito Administrativo. Membro fundador do Instituto de Direito Administrativo de Santa Catarina (IDASC). Vice-Diretor Geral da Escola Superior da Advocacia da OAB/SC (triênio 2013-2015). Conselheiro Estadual da OAB/SC (triênio 2013-2015). Membro da Comissão da Moralidade Pública da OAB/SC (triênio 2013-2015). Membro da Comissão de Direito Constitucional da OAB/SC (triênio 2013-2015). Assessor Jurídico do Sindicato dos Trabalhadores na Rede Estadual de Ensino de Santa Catarina (SINTE/SC). Advogado militante na seara do Direito Público, Sócio do Escritório Cristóvam \& Palmeira Advogados Associados S/C (www.cpadvogados.adv.br). E-mail: jscristovam@gmail.com 
resse público compatível com essa nova engenharia constitucional, indelevelmente marcada pelo traço humanista da personalização da ordem normativa constitucional. Esse novo marco normativo e político-institucional indica a superação da tradicional centralidade do princípio da supremacia do interesse público sobre o particular, propalado como princípio estruturante do regime jurídico administrativo, com a sua readequação aos novos vetores normativos do Estado constitucional de direito, fundado na defesa dos direitos fundamentais e no primado da dignidade humana.

Palavras-chave: Interesse público. Estado constitucional de direito. Princípio da supremacia do interesse público. Regime jurídico administrativo. Dignidade da pessoa humana.

\section{INTRODUÇÃO}

A nova ordem constitucional brasileira, inaugurada com o advento da aclamada "Constituição cidadã", veio a lume em meio a uma atmosfera festiva e cercada de alvissareira esperança democrática. É certo, porém, como já dito alhures, que vencidas as duas primeiras décadas e, por assim dizer, "atingida a 'maioridade civil' da (ainda político-socialmente infante) 'abertura democrática' brasileira”, há ainda um enorme déficit de concretização das promessas constitucionais. Ao que parece, a "Constituição de 1988, multicolorida pela vivificadora e extensa aquarela de direitos sociais constitucionalizados, acaba dando sinais de fenecimento (ou, quem sabe, somente saturação!), ante a rarefeita concretização de várias das suas promessas emancipatórias, libertárias e de igualdade social” (CRISTÓVAM, 2011, p. 11).

Por outro lado, resta inegável a profunda virada jurídico-metodológica operada a partir da Constituição de 1988, com o estabelecimento de uma prodigiosa carta de direitos fundamentais, situando a dignidade da pessoa humana como fundamento da República Federativa do Brasil (art. 1º, III da Constituição 
Federal), em um claro deslocamento do epicentro da ordem normativa para a pessoa humana.

Essa inequívoca "personalização da ordem constitucional" implica a necessária revisão de uma série de institutos que povoam os mais diversos ramos jurídicos. E o Direito Administrativo não está imune a esses ventos de constitucionalização ${ }^{3}$, o que vem ocorrendo, por exemplo, a partir do debate crítico acerca da "supremacia do interesse público" enquanto princípio estruturante do regime jurídico administrativo.

A tradicional doutrina administrativista que assentava o regime jurídico administrativo sob as balizas do princípio da supremacia do interesse público sobre o privado ${ }^{4}$, amplamente difundida e historicamente aceita quase sem contestação, passou recentemente a sofrer uma série de importantes e qualificadas críticas, que propõem uma interessante e sofisticada releitura do regime jurídico administrativo, a partir dos paradigmas do Estado constitucional de direito, da ponderação de interesses e da teoria dos direitos fundamentais ${ }^{5}$.

3 Para uma abalizada e panorâmica análise do movimento de "constitucionalização do direito", a partir do marco do neoconstitucionalismo, consultar: BARROSO, Luís Roberto. Neoconstitucionalismo e constitucionalização do direito: o triunfo tardio do Direito Constitucional no Brasil. Boletim da Faculdade de Direito da Universidade de Coimbra, v. LXXXI, 2005, p. 233-289. Da mesma forma, para estudos mais específicos acerca do fenômeno da constitucionalização do Direito Administrativo, consultar: BARROSO, Luís Roberto. A constitucionalização do direito e suas repercussões no âmbito administrativo. In: ARAGÃO, Alexandre dos Santos; MARQUES NETO, Floriano de Azevedo (Coord.). Direito Administrativo e seus novos paradigmas. Belo Horizonte: Fórum, 2008, p. 31-63; DI PIETRO, Maria Sylvia Zanella. Da constitucionalização do Direito Administrativo: reflexos sobre o princípio da legalidade e a discricionariedade administrativa. In: DI PIETRO, Maria Sylvia Zanella; RIBEIRO, Carlos Vinícius Alves (Coord.). Supremacia do interesse público e outros temas relevantes do Direito Administrativo. São Paulo: Atlas, 2010, p. 175-196; FALDINI, Cristiana Corrêa Conde. A constitucionalização do Direito Administrativo. In: DI PIETRO, Maria Sylvia Zanella; RIBEIRO, Carlos Vinícius Alves (Coord.). Supremacia do interesse público e outros temas relevantes do Direito Administrativo. São Paulo: Atlas, 2010, p. 261-277.

4 O estudo do princípio da supremacia do interesse público, enquanto princípio estruturante do regime jurídico administrativo, pode ser empreendido a partir da obra do seu maior difusor e grande publicista brasileiro: BANDEIRA DE MELLO, Celso Antônio. Curso de Direito Administrativo. 19. ed. São Paulo: Malheiros, 2005, p. 58 e ss.

5 Para uma análise crítica acerca do princípio da supremacia do interesse público, a partir das teorias da ponderação de interesses e dos direitos fundamentais, consultar: BINENBOJM, Gustavo. Uma teoria do Direito Administrativo: direitos fundamentais, democracia e constitucionalização. 2. ed. São Paulo: Renovar, 2008; 
A idéia de "supremacia do interesse público", alçada à condição de verdadeiro axioma do moderno Direito Público, acabou por ser entronado no posto máximo e inapelável de justificação de toda a atividade administrativa. Como um "verdadeiro mantra de legitimação da atividade administrativa”, o argumento da supremacia do interesse público a tudo explica e tudo justifica, inclusive escamoteando toda sorte de arbitrariedades, autoritarismos e ofensas aos princípios constitucionais (mormente a impessoalidade e a moralidade administrativa). Tudo passou a ser "legitimado" a partir de uma retórica frouxa e órfã de racionalidade, o que não escapou à percuciente crítica do constitucionalista Lenio Luiz STRECK, para quem o interesse público traduz-se atualmente em uma "expressão que sofre de intensa 'anemia significativa', nela 'cabendo qualquer coisa"'.

$\mathrm{Na}$ literatura jurídica nacional pós-abertura constitucional, coube ao jusfilósofo José Eduardo FARIA uma das primeiras análises críticas acerca da noção de interesse público, já atento à inafastável problemática dos recorrentes conflitos entre legítimos interesses contrapostos (públicos e privados), traço comum em uma Constituição aberta e pluralista como a nossa. Denunciando o caráter excessivamente vago e genérico do conceito de "interesse público", FARIA o descreve como "um conceito quase mítico, cujo valor se assenta justamente na indefinição de seu sentido e que, por ser facilmente manipulável por demagogos, populistas e tiranos da vida pública, acaba sendo analiticamente pobre" (FARIA, 1992, p. 173).

Esse é o cenário jurídico-político no qual se insere a tônica central do presente ensaio (uma análise muito mais panorâmica do que aprofundada, e sem quaisquer pretensões de esgotar

SARMENTO, Daniel (Org.). Interesses públicos versus interesses privados: desconstruindo o princípio da supremacia do interesse público. Rio de Janeiro: Lúmen Júris, 2005.

6 A expressão é de Lenio Luiz STRECK, em recente artigo publicado no sítio "Consultor Jurídico", onde aborda a problemática dos limites à atuação do Poder Judiciário e o desprestígio à lei, a partir da multifuncional e oca retórica da defesa do "interesse público". STRECK, Lenio Luiz. Ministros do STJ não devem se aborrecer com a lei. Disponível em: <http://www.conjur.com.br/2012-jun-07/senso-incomum-nao-aborreca-lei-ministra-nancy-andrighi>. Acesso em: 09 de jun. 2012. 
a temática, até pela sua elevada complexidade e pelos limites próprios desse texto): partindo da premissa de que o Estado constitucional de direito ${ }^{7}$ (fundado na teoria dos direitos fundamentais $^{8}$ e na centralidade do princípio da dignidade da pessoa humana ${ }^{9}$ ) engendra uma profunda redefinição dos contornos do regime jurídico administrativo, impõe-se a construção de

7 Analisando o fenômeno do Estado de direito a partir de uma perspectiva diacrônica, o jusfilósofo Sérgio CADEMARTORI divide a progressiva consolidação deste modelo de Estado em "governo per leges", "governo sub lege" e "Estado constitucional de direito". O aparato de dominação per leges constitui-se num poder que se expressa por meio de leis gerais e abstratas, decorrentes da vontade geral. Os atributos de generalidade e abstração da norma jurídica garantem a igualdade formal e afastam o arbítrio da ação governamental, vez que vinculam os poderes às formalidades e procedimentos dispostos em lei. No "governo sub lege" ocorre a vinculação e submissão dos poderes ao Direito, condicionando, além das formalidades e procedimentos da ação governamental, o conteúdo de tal ação, vinculando o governo a determinadas matérias. O Estado constitucional marca o caráter plenamente normativo e vinculante das Constituições, implicando na superação da redução positivista do Direito à lei e do jurídico ao legislativo. Deste modo, os direitos fundamentais passam a se constituir em matérias sobre as quais os poderes do Estado não podem dispor, uma vez que se constituem no fundamento de legitimidade do próprio Estado e expressão inarredável das democracias modernas. A garantia dos direitos fundamentais de liberdade e a concretização dos direitos fundamentais positivos é o dever primeiro do Estado, condição de legitimidade dos poderes constituídos. CADEMARTORI, Sérgio. Estado de direito e legitimidade: uma abordagem garantista. 2. ed. Campinas (SP): Millennium, 2007, p. 06-26.

8 Muito embora de suma relevância ao debate acerca do conceito de interesse público no Estado constitucional de direito, transcende aos limites do presente ensaio a abordagem da teoria dos direitos fundamentais. Para tal propósito, pode-se consultar: ALEXY, Robert. Teoria de los derechos fundamentales. Madrid: Centro de Estudios Constitucionales, 1993; ANDRADE, José Carlos Vieira de. Os direitos fundamentais na Constituição portuguesa de 1976. 5. ed. Coimbra: Almedina, 2012; SARLET, Ingo Wolfgang. A eficácia dos direitos fundamentais. 9. ed. Porto Alegre: Livraria do Advogado, 2007; SARLET, Ingo Wolfgang; TIMM, Luciano Benetti (Org.). Direitos fundamentais, orçamento e reserva do possível. 2. ed. Porto Alegre: Livraria do Advogado, 2010; TORRES, Ricardo Lobo. A Constituição de 1988 e a teoria dos direitos fundamentais. In: VIEIRA, José Ribas (Org.). 20 anos da Constituição cidadã: efetivação ou impasse institucional? Rio de Janeiro: Forense, 2008, p. 271-290.

9 Ainda que a temática afeta ao princípio da dignidade da pessoa humana e sua centralidade no Estado constitucional de direito sejam capitais ao presente estudo, sua análise exigiria vários aportes teóricos que transbordariam aos limites desse ensaio. Para tal empreitada, pode-se consultar: HABERMAS, Jürgen. Um ensaio sobre a Constituição da Europa. Coimbra: Almedina, 2012, p. 27-57; MIRANDA, Jorge. A dignidade da pessoa humana e a unidade valorativa do sistema de direitos fundamentais. In: MIRANDA, Jorge (Org.). Estudos em homenagem ao Prof. Doutor Martim de Albuquerque. vol. I. Coimbra: Coimbra Editora, 2010, p. 933949; MIRANDA, Jorge; SILVA, Marco Antonio Marques da (Coord.). Tratado luso-brasileiro de dignidade humana. São Paulo: Quartier Latin, 2008; SARLET, Ingo. Dignidade da pessoa humana e direitos fundamentais na Constituição Federal de 1988. 3. ed. Porto Alegre: Livraria do Advogado, 2004. 
um conceito de interesse público compatível com essa nova engenharia constitucional, indelevelmente marcada pelo traço humanista da "personalização da ordem normativa constitucional".

Inequivocamente, em uma ordem constitucional caracterizada pelo movimento de constitucionalização de uma complexa, dinâmica e (por vezes!) colidente gama de interesses individuais (privados) e coletivos (públicos), a problemática da concretização e defesa desses legítimos interesses passa pela redefinição dos parâmetros do regime jurídico administrativo, a partir da análise dos contornos e limites de um conceito de interesse público afinado ao novo quadrante constitucional.

Isso impõe, inclusive, a superação da tradicional centralidade do princípio da supremacia do interesse público sobre o particular, propalado como princípio estruturante do regime jurídico administrativo, bem como sua adequação aos novos vetores normativos do Estado constitucional de direito, fundado na defesa dos direitos fundamentais e no primado da dignidade humana.

Antes, porém, do debate acerca dos atuais contornos e parâmetros do conceito de interesse público, faz-se imperiosa uma breve recuperação das teorias jurídico-filosóficas que têm indelevelmente marcado a metodologia constitucional contemporânea, servindo de inexorável substrato ao estabelecimento de um conceito de interesse público consentâneo ao Estado constitucional de direito que o ampara.

\section{O ESTADO CONSTITUCIONAL DE DIREITO E AS BASES JURÍDICO-FILOSÓFICAS PARA O ATUAL CONCEITO DE INTERESSE PÚBLICO}

Por certo, o atual conceito de interesse público não pode ser estruturado, de forma atropelada e descontextualizada, no nascente Estado liberal de direito ${ }^{10}$ e no palco instaurado pela

10 A expressão "Estado liberal de direito" é utilizada pelo simples fato de ter sido consagrada pela ciência política, mesmo não sendo a mais coerente. Em última análise, o atual modelo de Estado também pode ser definido como liberal, já que 
histórica Revolução Francesa, muito embora tenha sido nesse efervescente e singular momento que se tenham forjado os seus contornos originais, em meio ao advento do próprio Direito Administrativo enquanto ramo autônomo do Direito.

$\mathrm{O}$ conceito de interesse público comum àquele modelo jurídico de cunho marcadamente liberal e individualista, no mais das vezes indiferente às pressões das massas populares e às lutas pelo direito a ter direitos (substancias), deve ser suplantado por um conceito de interesse público adequado ao atual modelo de "Estado de direito inclusivo", que assume obrigações perante os cidadãos e procura dialogar com os anseios dos mais diferentes conjuntos de atores sociais, aqui nomeado de Estado constitucional de direito.

Como já defendido alhures ${ }^{11}$, esse modelo de Estado de direito inclusivo (Estado constitucional de direito) vem acompanhado por um sofisticado marco teórico, que pretende a superação das teorias do positivismo jurídico e a consolidação de uma nova teoria da Constituição. Por certo, não se pode desvincular as mudanças teóricas que respaldaram a passagem do positivismo jurídico para o pós-positivismo ${ }^{12}$ ou neoconsti-

garante inúmeros direitos individuais e, cada vez mais, diminui sua intervenção na economia, conduzindo-se à forma de Estado mínimo. Em verdade, dever-se-ia falar em "Estado legal", já que, com a derrocada do Estado absolutista e a ascensão do Estado de direito, houve, de fato, uma verdadeira substituição do império da vontade do monarca pelo império da vontade da lei, uma espécie de totem da racionalidade moderna. A lei passou a ser a vontade soberana, sob a qual se colocaram o Estado e os cidadãos. Para um estudo aprofundado acerca do Estado liberal e a passagem para o Estado social, pode-se consultar: BONAVIDES, Paulo. Do Estado liberal ao Estado social. 6. ed. rev. e ampl. São Paulo: Malheiros, 1996; LUCAS VERDÚ, Pablo. Estado liberal de derecho y Estado social de derecho. Madrid: Universidad de Salamanca, 1955; PEREZ LUNÕ, Antonio Enrique. Derechos humanos, Estado de derecho y Constituición. 5. ed. Madrid: Tecnos, 1994.

11 A temática do Estado constitucional de direito sob o marco do neoconstitucionalismo, aqui brevemente recuperada, foi abordada anteriormente no seguinte artigo: CRISTÓVAM, José Sérgio da Silva. Direitos sociais e controle ..., p. 11-13.

12 Para um estudo mais aprofundado acerca do pós-positivismo, pode-se consultar, entre outros: CALSAMIGLIA, Albert. Postpositivismo. Cuadernos de Filosofía del Derecho, n. 21-I, Doxa, 1998, p. 209-220. No Brasil, o termo "pós-positivismo" é usado com forte semelhança de sentido, entre outros, pelo constitucionalista Paulo BONAVIDES. BONAVIDES, Paulo. Curso de Direito Constitucional. 10. ed. São Paulo: Malheiros, 2000, p. 228-66. 
tucionalismo ${ }^{13}$, das profundas mudanças sociais e econômicas evidenciadas no curso do Século $X^{14}$.

O neoconstitucionalismo não pode ser encarado como uma proposta acabada de teoria do direito, com pretensões de sistematicidade e adequação. $\mathrm{Na}$ verdade, sob o rótulo ainda em construção do neoconstitucionalismo, reúnem-se diversas doutrinas de teoria constitucional, por vezes até entre si contraditórias. Umas mais radicais e inconciliáveis até com os mais abertos modelos de "positivismo jurídico crítico"15; outras,

13 A expressão "neoconstitucionalismo" é aqui empregada para caracterizar um modelo teórico que vem ganhando expressão e lastro na cultura jurídica a partir da segunda metade do século $X X$, baseado na superação das idéias que marcam o positivismo jurídico, principalmente no que concerne à relação de tensão entre Direito e moral. No decorrer desse trabalho o neoconstitucionalismo será preferido à equivalente expressão "pós-positivismo". Em sentido semelhante, o pensamento de jusfilósofo espanhol Manuel Atienza. ATIENZA, Manuel. Entrevista a Robert Alexy. Cuadernos de Filosofía del Derecho, n. 24, Doxa, 2001, p. 672-73.

$14 \mathrm{O}$ positivismo jurídico, aqui entendido como aquela teoria jurídica que encara o direito positivo como o único objeto da "ciência jurídica" e que não admite a conexão entre o Direito, a moral e a política, servia a um modelo de sociedade, o modelo liberal-individualista. Em uma sociedade marcada pela homogeneidade política e igualdade formal jurídica, o sistema normativo que melhor garante a propriedade e a liberdade de mercado é, por certo, o sistema de regras. Ante a mudança do cenário social, a consolidação dos movimentos de classe, o fortalecimento de novos atores sociais, o pluralismo político e jurídico, a heterogeneidade política da sociedade, evidencia-se a necessidade de repensar as bases teóricas do Direito. Neste sentido, fala-se em neoconstitucionalismo, entendido como a teoria contemporânea que procura enfrentar os problemas da indeterminação do Direito, sustentando uma situação de estreita relação entre Direito, moral e política. Para um estudo mais aprofundado acerca do neoconstitucionalismo, pode-se consultar: CARBONELL, Miguel (Coord.). Neoconstitucionalismo(s). 2. ed. Madrid: Trotta, 2005; CARBONELL, Miguel (Coord.). Teoría del neoconstitucionalismo: ensaios escogidos. Madrid: trotta, 2007; SARMENTO, Daniel. O neoconstitucionalismo no Brasil: riscos e possibilidades. In: LEITE, George Salomão; SARLET, Ingo Wolfgang (Org.). Direitos fundamentais e Estado Constitucional: estudos em homenagem a J. J. Gomes Canotilho. São Paulo; Coimbra: Revista dos Tribunais; Coimbra Editora, 2009, p. 09-49.

15 Sobre o positivismo jurídico crítico, pode-se estudar a teoria do garantismo jurídico do jusfilósofo italiano Luigi FERRAJOLI. Sua teoria representa um sofisticado modelo de positivismo jurídico crítico, que pretende a sólida limitação dos poderes públicos constituídos (Estado de direito) e efetiva defesa dos direitos fundamentais, mas sem incorrer nos graves déficits de legitimidade e indeterminação do ativismo judicial ponderacionista (argumentação de princípios). Para um estudo aprofundado do garantismo jurídico, pode-se consultar: CARBONELL, Miguel; SALAZAR, Pedro (Coord.). Garantismo: estudios sobre el pensamiento jurídico de Luigi Ferrajoli. Madrid: Trotta, 2005; CADEMARTORI, Sérgio. Estado de direito ..., 2007; FERRAJOLI, Luigi. Garantismo: una discusión sobre derecho y democracia. Madrid: Trotta, 2006; FERRAJOLI, Luigi. Derecho y razón: teoría del garantismo penal. 4. ed. Madrid: Trotta, 2000. 
porém, em larga medida conciliáveis com esses últimos. Por outro lado, em maior ou menor amplitude, todas essas doutrinas estão voltadas à consolidação de uma sólida teoria da supremacia da Constituição, da defesa da força normativa dos princípios constitucionais, da eficácia dos direitos fundamentais, da interpretação conforme a Constituição e da centralidade do princípio da dignidade de pessoa humana.

A supremacia da Constituição e o caráter vinculante dos direitos fundamentais são traços característicos fundantes do Estado constitucional de direito, um modelo de Estado de direito pautado pela força normativa dos princípios constitucionais ${ }^{16}$ e pela consolidação de um modelo de justiça substancial ${ }^{17}$.

A análise do nosso sistema jurídico constitucional não prescinde, em hipótese alguma, de um profundo estudo acerca dos princípios constitucionais. A força normativa da Constituição depende diretamente da oxigenação de princípios que tenham lastro no corpo social. Por certo, a Constituição será sempre mais efetiva e vivificada na sociedade, quanto maior a interação dos princípios constitucionais com as aspirações dos cidadãos a ela submetidos. Essas são as bases jurídico-filosóficas sob as quais se deve erigir o atual conceito de interesse público, objeto central do presente ensaio.

$16 \mathrm{O}$ estudo mais aprofundado acerca da teoria dos princípios constitucionais pode ser buscado em: CRISTÓVAM, José Sérgio da Silva. Colisões entre princípios constitucionais: razoabilidade, proporcionalidade e argumentação jurídica. 1. ed. 4. tir. Curitiba: Juruá, 2011; ÁVILA, Humberto. Teoria dos princípios: da definição à aplicação dos princípios jurídicos. 4. ed. São Paulo: Malheiros, 2004; ESPÍNDOLA, Ruy Samuel. Conceito de princípios constitucionais: elementos teóricos para uma formulação dogmática constitucionalmente adequada. 2. ed. São Paulo: Revista dos Tribunais, 2002.

17 Debatendo acerca desse novo modelo de Estado de direito, o professor BONAVIDES ensina que, "com a queda do positivismo e o advento da teoria material da Constituição, o centro de gravidade dos estudos constitucionais, que dantes ficava na parte organizacional da Lei Magna - separação de poderes e distribuição de competências, enquanto forma jurídica de neutralidade aparente, típica do constitucionalismo do Estado Liberal - se transportou para a parte substantiva, de fundo e conteúdo, que entende com os direitos fundamentais e as garantias processuais da liberdade, sob a égide do Estado social". BONAVIDES, Paulo. Curso de Direito..., p. 584. 


\section{O INTERESSE PÚBLICO NO DIVÃ: PARA UM CONCEITO DE INTERESSE PÚBLICO}

A construção de um conceito de interesse público não é, certamente, uma empreitada singela. Há quem defenda, inclusive, que o interesse público acabe por ser infenso ao aprisionamento em uma noção propriamente conceitual (que ostente um conteúdo determinado). Seria, portanto, uma noção muito mais funcional e dinâmica do que conceitual, podendo apresentar inúmeras variações segundo critérios quantitativos e qualitativos, se apurado em diferentes épocas (tempo) e países (espaço) (VEDEL, 1980, p. 257-60). Inclusive, essa dificuldade em estabelecer um conceito de interesse público levou o administrativista argentino Guillermo Andrés MUÑOZ a defender (de forma lapidar e até poética!) que o interesse público é como o amor: é mais fácil sentir do que definir! (MOÑZ, 2010, p. 21-31).

Ante a sua característica fluidez conceitual, há quem qualifique a idéia de interesse público como verdadeiro topoi ${ }^{18}$, um lugar comum (loci), e que por isso mesmo dispensaria uma definição mais precisa, até para facilitar sua adequada e eficiente aplicação (FERRAZ JUNIOR, 1995, p. 10).

A aventada dificuldade em definir o interesse público também não escapou à aguçada lente do administrativista espanhol Jaime RODRÍGUEZ-ARANA MUÑOZ, atribuindo-lhe, dentre outras particularidades, ao fato de estar visceralmente ligado à realidade, não existindo a sua margem ou dela afastado. O interesse público restaria descortinado e projetado a partir da sua operação de materialização, precipuamente promovida pela Administração Pública. Mas isso não equivale dizer, por outro lado, que não existam parâmetros de aferição racional e normativa do interesse público, que reside atualmente "no marco dos princípios informadores do Estado social e democrático de Direito" (RODRÍGUEZ-ARANA MUÑOZ, 2010, p. 42).

18 Para um estudo mais aprofundado acerca da tópica jurídica, pode-se consultar: CRISTÓVAM, José Sérgio da Silva. Colisões entre princípios..., p. 121-32; VIEHWEG, Theodor. Tópica y jurisprudencia. Traducción de Luis Díez-Picazo Ponce de Leon. Madrid: Taurus, 1964. 
Neste contexto, algumas questões assumem capital relevância, merecendo uma abordagem mais detida (ainda que não exaustiva, ante os limites do presente ensaio!): O interesse público pode ser considerado um conceito universal? Quem pode legitimamente definir o que seja o interesse público? A quem compete aplicar tais definições e determinar o seu conteúdo e abrangência? E quais os limites ao controle judicial acerca do conteúdo do interesse público concretamente aplicado ${ }^{19}$ ?

A noção de interesse público, com esta ou outra designação ${ }^{20}$ (bem comum ${ }^{21}$, interesse geral ${ }^{22}$ ), sempre acompanhou a civilização humana. Esse é o entendimento de RODRÍGUEZ-ARANA MUÑOZ, para quem desde sempre os homens têm se organizado para questões de interesses comuns, quer locais, quer gerais; quer na defesa de interesses de coletividades profissionais, quer para gerir ou administrar interesses supraindividuais em geral (RODRÍGUEZ-ARANA MUÑOZ, 2010, p. 35).

19 Alguns desses questionamentos são apresentados por MUÑOZ, como preocupações fundamentais que têm interessado à comunidade jurídica alemã. Neste sentido, ver: MUÑOZ, Guillermo Andrés. El interés público..., p. 22.

20 Muito embora parcela considerável da doutrina e da jurisprudência dos tribunais, bem como, por vezes, o próprio direito positivo, tenham indicado uma relação de sinonímia e empregado de forma indistinta as expressões interesse público, interesse geral, bem comum, interesse coletivo, etc., não se pode olvidar a possibilidade de diferenciação, a partir de parâmetros filosóficos, políticos e de teoria do Estado, contribuindo para a construção de um conceito de interesse público afinado como atual modelo de Estado constitucional de direito. Neste sentido, consultar: DURÁN MARTÍNEZ, Augusto. Derechos prestacionales e interés público. In: BACELLAR FILHO, Romeu Felipe; HACHEM, Daniel Wunder (Coord.). Direito Administrativo e interesse público: estudos em homenagem ao Professor Celso Antônio Bandeira de Mello. Belo Horizonte: Fórum, 2010, p. 145-149.

21 Para uma análise da idéia de interesse público a partir da noção de bem comum, consultar: DI PIETRO, Maria Sylvia Zanella. O princípio da supremacia do interesse público: sobrevivência diante dos ideais do neoliberalismo. In: DI PIETRO, Maria Sylvia Zanella; RIBEIRO, Carlos Vinícius Alves (Coord.). Supremacia do interesse público e outros temas relevantes do Direito Administrativo. São Paulo: Atlas, 2010, p. 86-91.

22 A Constituição Espanhola de 1978 (artigo 103, 1) assegura que "la Administración Pública sirve con objetividad los intereses generales...". Para uma análise da noção de interesses gerais na ordem constitucional espanhola, consultar: MEILÁN GIL, José Luis. Intereses generales e interés público desde la perspectiva del Derecho Público español. In: BACELLAR FILHO, Romeu Felipe; HACHEM, Daniel Wunder (Coord.). Direito Administrativo e interesse público: estudos em homenagem ao Professor Celso Antônio Bandeira de Mello. Belo Horizonte: Fórum, 2010, p. 65-88. 
Por outro lado, ainda que se possa buscar a construção de uma noção de interesse público já na Antiguidade (sobretudo a partir da idéia de bem comum), não se pode negar que a sua acentuada centralidade ocorre a partir do advento da Modernidade, associada às construções dos ideais do Estado de direito, da separação de poderes, dos conceitos de interesses individuais (privados) e coletivos (públicos), em meio ao substrato político e filosófico do qual germinou o próprio Direito Administrativo moderno 23 .

Questão de inequívoca pertinência refere-se ao debate em torno do suposto caráter de validade universal do conceito de interesse público, que ostentaria uma noção geral e abstrata da qual seria possível extrair uma idéia de seu conteúdo e significação (RODRÍGUEZ-ARANA MUÑOZ, 2010, p. 36). Sobre o tema, cabe recordar o escólio do jurista Dalmo de Abreu DALLARI, que há mais de duas décadas atrás defendia a impossibilidade de uma "consideração genérica, prévia e universalmente válida do que seja o interesse público, revelando-se inevitável a avaliação pragmática do que é interesse público. Em cada

23 Mostra-se corrente a doutrina que sustenta um caráter garantista e emancipatório na gênese do Direito Administrativo, operando uma ruptura com o Antigo Regime absolutista e funcionando como instrumento de limitação do poder estatal. Entretanto, essa noção vem sofrendo abalizadas críticas, a partir de uma releitura do contexto histórico do seu nascimento, bem como de uma série de seus institutos (supremacia do interesse público, contencioso administrativo, poder de polícia, discricionariedade, mérito administrativo, etc.). Na leitura dessa corrente de contestação, esses institutos representariam muito mais fortemente a continuidade de uma lógica de autoridade (de matriz monárquica) do que a sua ruptura, a partir da construção de uma lógica garantista de defesa dos direitos individuais e limitação do poder estatal. Para uma análise crítica acerca da gênese garantista do Direito Administrativo, consultar: OTERO, Paulo. Legalidade e Administração Pública: o sentido da vinculação administrativa à juridicidade. Coimbra: Almedina, 2007, p. 269-282; SILVA, Vasco Pereira da. O contencioso administrativo no divã da psicanálise: ensaio sobre as acções no novo processo administrativo. 2. ed. Coimbra: Almedina, 2009, p. 09-13; BINENBOJM, Gustavo. Uma teoria do Direito ..., p. 09-22. Para uma "crítica da crítica" e o afastamento das idéias de uma gênese autoritária do Direito Administrativo, consultar: GABARDO, Emerson; HACHEM, Daniel Wunder. O suposto caráter autoritário da supremacia do interesse público e das origens do Direito Administrativo: uma crítica da crítica. In: BACELLAR FILHO, Romeu Felipe; HACHEM, Daniel Wunder (Coord.). Direito Administrativo e interesse público: estudos em homenagem ao Professor Celso Antônio Bandeira de Mello. Belo Horizonte: Fórum, 2010, p. 155-201. 
situação será indispensável fazer a verificação, uma vez que não há um interesse público válido universalmente" (DALLARI, 1987, p. 15).

Nada obstante, e partindo de uma concepção estritamente normativa de universalização, seria possível defender a idéia de um caráter universal do conceito de interesse público, com base, por exemplo, em pautas assecuratórias do primado dos direitos humanos, sobretudo a partir da Declaração Universal dos Direitos Humanos de 1948. A universalidade do conceito de interesse público passaria, necessariamente, pelo reconhecimento da primazia dos direitos fundamentais, valores que devem ser colocados acima de quaisquer interesses ocasionais, acima de quaisquer governos, governantes, Estados e das próprias pessoas as quais se pretende defender.

Mas a idéia de universalidade do conceito de interesse público não ilide a problemática relacionada à definição do seu conteúdo e significação. Partindo-se da premissa de que em um Estado constitucional de direito vigora o primado da Constituição como norma fundamental do sistema jurídico-político do Estado, não se pode conceber outro espaço legítimo de concretização dos valores e interesses aceitos como válidos em uma dada sociedade política, que não primeiramente a Constituição.

Em diversos casos, inclusive, a própria ordem constitucional define, expressamente, a preponderância de determinado interesse sobre os demais (quer públicos, quer privados), como ocorre, v. g., no caso do artigo $5^{\circ}$, XXIV da Constituição de 1988, que prevê a possibilidade de "desapropriação por necessidade ou utilidade pública, ou por interesse social, mediante justa e prévia indenização em dinheiro", submetendo o interesse privado (individual) ao interesse público (coletividade). Em outras situações, a Constituição acaba por prever uma ordem limitadora de um determinado direito ou interesse, mas transfere ao legislador ordinário a atribuição de estabelecer os contornos da referida limitação. Isso ocorre, v. g., quando o artigo 5, XXIII da Constituição de 1988 determina que "a propriedade atenderá a sua função 
social", sendo que o seu artigo 186 estabelece os requisitos pelos quais restaria cumprida a aludida função social da propriedade, mas deixa para a lei ordinária a fixação dos respectivos critérios e graus de exigência.

Quando a Constituição estabelece uma relação de prevalência de determinado direito ou interesse, não se pode admitir como legítima outra interpretação que não aquela comprometida com a supremacia constitucional. Da mesma forma, ressalvados os casos de vícios de inconstitucionalidade, há que se reconhecer a prevalência das escolhas políticas do órgão legislativo, sob pena, inclusive, de grave ofensa ao princípio democrático e ao primado da legalidade.

Mas o certo é que, tanto no caso da ausência de parâmetros normativos definitivos, bem como pela própria complexidade e acirrada disputa entre direitos e interesses que povoam uma ordem constitucional aberta e plural, compete à Administração Pública a função de concretização dos conteúdos, a definição política dos limites e abrangências dos direitos e interesses assegurados pela Constituição e pelas leis. Não a partir de qualquer parâmetro vago e irracional de supremacia do interesse público, mas sim com base em modernas técnicas e critérios de ponderação dos interesses em jogo (justificadas por uma sólida teoria da argumentação jurídica), levando em consideração as circunstâncias e peculiaridades da situação concreta.

Isso acarreta não somente o afastamento de uma justificação a priori das escolhas político-administrativas, com base em um totêmico parâmetro (vazio e incontrolável) de supremacia do interesse público, mas impõe também a obrigação da Administração Pública declinar todas as razões e justificativas de suas escolhas - o que antes vinha acobertado por um arremedo de justificação, baseado nas (tão famosas quanto ocas!) "razões de interesse público".

A superação da noção de supremacia do interesse público favorece e torna mais efetivo, inclusive, o próprio controle jurisdicional da atividade administrativa, uma vez que impõe ao juiz 
(guardião da Constituição e das leis) o dever de perquirir acerca da conformação constitucional ou legal das escolhas da Administração Pública, mas agora com base em efetivas justificativas e motivações e não limitado ao quase intransponível dogma da prevalência prima facie do interesse público.

Segundo o pensamento de Celso Antônio BANDEIRA DE MELLO, o "interesse público deve ser conceituado como o interesse resultante do conjunto dos interesses que os indivíduos pessoalmente têm quando considerados em sua qualidade de membros da Sociedade e pelo simples fato de o serem" (BANDEIRA DE MELLO, 2005, p. 51).

Aprofundando o debate, Marçal JUSTEN FILHO propõe uma conceituação negativa de interesse público, ou seja, a partir daquilo que não configura o conceito ou com ele se confunde, a fim de chegar àquilo que poderia ser assim definido. Primeiramente, defende que o interesse público não se confunde com o interesse do Estado, já que este é sim instrumento de realização daquele. O interesse público sequer é essencialmente de titularidade do Estado, já que existem interesses públicos não estatais, como o caso do chamado terceiro setor. Por outro lado, sob as balizas de uma Constituição republicana e democrática como a nossa, não se pode entender o Estado senão como instrumento de satisfação dos interesses públicos, ou seja, a consecução dos direitos fundamentais, instância última de legitimação da própria estrutura estatal (JUSTEN FILHO, 2005, p. 37).

Da mesma forma, "nenhum 'interesse público' se configura como "conveniência egoística da administração pública”, já que o chamado interesse secundário ou interesse da Administração Pública não é público, sendo sequer verdadeiro interesse, mas mera conveniência circunstancial. Nem se confunde com os interesses do agente público, que deve pautar suas ações segundo os interesses da coletividade abstratamente considerada, e não interesses privados e egoísticos. O Estado "somente está legitimado a atuar para realizar o bem comum e a satisfação geral" (JUSTEN FILHO, 2005, p. 39). 
O interesse público também não pode, por certo, ser qualificado como o interesse da maioria da população, o que afrontaria sobremaneira ao princípio do Estado democrático de direito, destruindo e marginalizando os interesses das minorias, em uma perigosa supremacia ou ditadura dos interesses da maioria, esta quase sempre eventual, sazonal e manipulável.

$O$ interesse público (um conceito jurídico indeterminado ${ }^{24}$ ) não pode ser resumido a uma questão numérica, sob pena de afronta direta e extremamente perigosa ao princípio do Estado democrático de direito. Não se trata de um conceito quantitativo, mas sim qualitativo, devendo ser entendido como o interesse coletivo abstratamente considerado, a partir dos valores consolidados pelo sistema constitucional.

O interesse público é a expressão dos valores indisponíveis e inarredáveis assegurados pela Constituição, sob o signo inarredável dos direitos fundamentais e da centralidade do princípio da dignidade da pessoa humana (personalização da ordem constitucional). Não se deve, pois, buscar o interesse público (singular), mas os interesses públicos consagrados no texto constitucional, que inclusive podem se apresentar conflitantes na conformação do caso concreto, o que exige necessariamente uma ponderação de valores, a fim que resolver o conflito entre princípios no problema prático.

Com inteira razão, portanto, está JUSTEN FILHO quando defende que o conceito de interesse público envolve uma questão ética e não técnica. "Há demandas diretamente relacionadas à realização de princípios e valores fundamentais, especialmente a dignidade da pessoa humana... O ponto fundamental é a questão ética, a configuração de um direito funda-

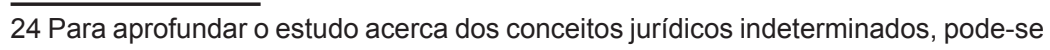
consultar: BANDEIRA DE MELLO, Celso Antônio. Discricionariedade e controle jurisdicional. 2. ed. 3. Tir. São Paulo: Malheiros, 1998; COSTA, Regina Helena. Conceitos jurídicos indeterminados e discricionariedade administrativa. Revista de Direito Público, Ano 23, n. 95, Jul./Set., São Paulo: Revista dos Tribunais, 1990; CRISTÓVAM, José Sérgio da Silva. A evolução do princípio de legalidade e o controle jurisdicional da discricionariedade administrativa. Revista Discente Interinstitucional (RDI), ano I, n. 1, jan./jun., Florianópolis: Fundação Boiteux, 2006. 
mental. Ou seja, o núcleo do direito administrativo não reside no interesse público, mas nos direitos fundamentais" (JUSTEN FILHO, 2005, p. 43-44).

\section{HÁ FUNDAMENTO CONSTITUCIONAL AO PRINCÍPIO DA SUPREMACIA DO INTERESSE PÚBLICO SOBRE O PRIVADO?}

A relevância do delineamento dos contornos do regime jurídico administrativo ${ }^{25}$ (conjunto ordenado e coerente de normas jurídicas) mostra-se inegável, porquanto afeto à conformação do Direito Administrativo enquanto disciplina jurídica autônoma. Enfrentando essa problemática, e partido da matriz publicista ao qual o Direito Administrativo está visceralmente ligado, o administrativista BANDEIRA DE MELLO defende que tal regime estaria fundado na "consagração de dois princípios: a) supremacia do interesse público sobre o privado; $b$ ) indisponibilidade, pela Administração, dos interesses públicos" (BANDEIRA DE MELLO, 2005, p. 45).

No mesmo quadrante, a professora Maria Sylvia Zanella DI PIETRO sustenta que o regime administrativo resume-se basicamente a duas idéias-chave: prerrogativas e sujeições. $\mathrm{O}$ Direito Administrativo gravitaria em torno da oposição bipolar das idéias de liberdade do indivíduo e autoridade da Administração, resultando a esta um conjunto de restrições e prerrogativas. As restrições serviriam para assegurar a liberdade do indivíduo, a partir da obediência ao princípio da legalidade administrativa. As prerrogativas e privilégios da Administração garantiriam a autoridade necessária à consecução de seus fins,

25 Para os fins do presente ensaio, a idéia de regime jurídico adotada é tributária do difundido conceito de sistema jurídico de Claus-Wilhelm CANARIS, fundado nas noções de adequação valorativa e a unidade interior da ordem jurídica. Para estudos complementares: CANARIS, Claus-Wilhelm. Pensamento sistemático e conceito de sistema na ciência do Direito. Tradução de António Menezes Cordeiro, 2. ed. Lisboa: Fundação Calouste Gulbenkian, 1996; FERRAZ JÚNIOR, Tércio Sampaio. Conceito de sistema no Direito. São Paulo: Revista dos Tribunais, 1976. 
sob o pálio do princípio da supremacia do interesse público sobre o particular ${ }^{26}$.

Retomando o escólio do professor BANDEIRA DE MELLO, o princípio da supremacia do interesse público é qualificado como "verdadeiro axioma reconhecível no moderno Direito Público", que sustenta a "superioridade do interesse da coletividade, firmando a prevalência dele sobre o do particular, como condição, até mesmo, da sobrevivência e asseguramento deste último" 2 .

Mas adverte o renomado administrativista que as prerrogativas e privilégios decorrentes da supremacia do interesse público somente podem ser empregados na exata consecução do interesse público. Não para satisfazer interesses ou conveniências do aparelho estatal ou dos seus agentes, o que tornaria ilegítima a atividade administrativa. Impõe-se, pois, a diferenciação entre interesses públicos primários e interesses públicos secundários, a partir da doutrina do administrativista italiano

26 Esses seriam, segundo a ilustre administrativista, os dois princípios fundamentais do Direito Administrativo (legalidade administrativa e supremacia do interesse público), sob os quais se construiriam todos os demais. DI PIETRO, Maria Sylvia Zanella. Direito Administrativo. 19. ed. São Paulo: Atlas, 2006, p. 78-81.

27 Segundo BANDEIRA DE MELLO, da supremacia do interesse público decorreriam, consequentemente, a posição privilegiada do órgão encarregado de zelar pelo interesse público e sua posição de supremacia nas relações com os particulares. Dessas conseqüências seriam exemplos a presunção de legitimidade e veracidade dos atos administrativos; os prazos processuais diferenciados; a posição de ré na maior parte dos feitos judiciais, deixando aos particulares a condição de autores, com seus ônus peculiares; os prazo prescricionais especiais; as situações que decorrem da condição de verticalidade da Administração Pública ante os particulares; a constituição unilateral dos particulares em obrigações; as modificações unilaterais em contratos administrativos; a exigibilidade dos atos administrativos; a revogação unilateral dos próprios atos e sua invalidação, quando eivados de vícios (autotutela). Já o princípio da indisponibilidade dos interesses públicos pela Administração significa que esses "não se encontram à livre disposição de quem quer que seja, por inapropriáveis. O próprio órgão administrativo que os representa não tem disponibilidade sobre eles, no sentido de que incumbe apenas curá-los - o que é também um dever - na estrita conformidade do que dispuser a intentio legis". Os bens e interesses não são postos à livre disposição da vontade do administrador. Desse princípio decorreriam os princípios da legalidade, finalidade, razoabilidade, proporcionalidade, motivação, responsabilidade do Estado, continuidade do serviço público, controle administrativo, isonomia, publicidade, inalienabilidade dos direitos concernentes a interesses públicos e do controle jurisdicional dos atos administrativos. BANDEIRA DE MELLO, Celso Antônio. Curso de Direito..., p. 58-64. 
Renato ALESSI. Os interesses públicos não podem ser confundidos com os interesses do Estado, do aparelho da Administração burocrática ou do erário, sendo que "os interesse secundários do Estado só podem ser por ele buscados quando coincidentes com os interesses primários, isto é, com os interesses públicos propriamente ditos" (ALESSI apud BANDEIRA DE MELLO, 2005, p. 58-64).

A tese que funda o regime jurídico administrativo sob o princípio da supremacia do interesse público sobre o privado, muito embora correntemente aceita e difundida, não parece sustentável se submetida aos vetores basilares da Constituição de 1988, sobretudo a partir do primado da pessoa humana e dos direitos fundamentais.

Cabe, primeiramente, atentar para o fato de que a qualificação do princípio da supremacia do interesse público como "verdadeiro axioma" do moderno Direito Público não está imune a críticas. Se entendida a idéia de axioma como uma proposição normativa autoevidente e aceita por todos, inclusive não sujeita ao debate jurídico ou qualquer tipo de argumentação demonstrativa, a única forma de aceitar a validade de tal doutrina seria a existência de um princípio constitucional expresso, o que não ocorre na nossa ordem constitucional.

Malgrado a inexistência de um princípio expresso que assegure a supremacia do interesse público, poder-se-ia defender o seu status constitucional como um princípio implícito, decorrente da própria ordem jurídico constitucional, mas já não mais sob a qualificação de "axioma". Esta empreitada é assumida pelo administrativista Fábio Medina OSÓRIO, para quem o princípio implícito da supremacia do interesse público resta assentado na existência de uma série de dispositivos constitucional que protegem inúmeros bens coletivos e restringem direitos individuais, o que legitimaria o regime de normas de privilégio conferido à Administração Pública para a consecução de seus fins (OSÓRIO, 2000, p. 87 e ss.). 
Nada obstante a sofisticada argumentação, não parece que seja possível extrair da Constituição um princípio que assegure (prima facie) a supremacia do interesse público. Ademais, não se pode admitir como válida a tese de que o conjunto de prerrogativas (ou, por vezes, verdadeiros privilégios!) da Administração Pública possa ser, a priori, legitimado a partir da idéia de supremacia do interesse público, uma vez que dependerá sim do conjunto de valores e princípios constitucionais em jogo, a partir dos métodos e critérios consagrados pela hermenêutica constitucional contemporânea.

\section{CONCLUSÃO}

A admissão da existência de um princípio constitucional que assegure prima facie a prevalência absoluta (supremacia) do interesse público sobre o privado acaba por subverter a própria noção de princípios constitucionais, enquanto mandamentos de otimização que apontam para um determinado fim a ser alcançado. A noção de princípios constitucionais é totalmente inconciliável com qualquer idéia de um princípio absoluto, capaz de prevalecer (a priori) sobre os demais, independentemente das circunstâncias fáticas e jurídicas relacionadas.

Afastado o princípio da supremacia do interesse público como a "medida de todas as coisas" e o parâmetro capital de legitimação da atividade administrativa, verdadeira norma estruturante do regime jurídico administrativo, convém repensar os contornos e pressupostos do novo regime jurídico administrativo, nascido do deslocamento do foco de prevalência preponderantemente fixado no Estado, para a pessoa (cidadão) e a satisfação de seus interesses (públicos e privados).

O novo regime jurídico administrativo, marcado por essa matriz constitucional de personalização e prevalência dos direitos fundamentais, deve ser assentado no princípio da dignidade da pessoa humana, no Estado democrático de direito ${ }^{28} \mathrm{e}$

28 Para um estudo mais aprofundado acerca do princípio democrático e a idéia de democracia procedimental e de consenso, pode-se consultar: HABERMAS, 
no princípio republicano ${ }^{29}$, a partir de um processo de constitucionalização do Direito Administrativo e humanização (personalização) de seus contornos. No entrelaçamento dos princípios republicano, do Estado democrático de direito e da dignidade da pessoa humana, estão as bases para se repensar os contornos, limites e pressupostos de um novo regime jurídico administrativo, passando do tradicional "axioma" da supremacia do interesse público para o constitucionalizado parâmetro da ponderação de interesses.

A construção desse novo regime jurídico administrativo seguramente reclamará uma profunda reestruturação de diversos institutos e teorias que fundam a disciplina jurídico-administrativa, agora profundamente colonizada pela ordem constitucional. O conceito de interesse público passa, inequivocamente, pela carta de direitos fundamentais constitucionalmente assegurados, pelo princípio da dignidade da pessoa humana e pela teoria da ponderação de interesses, em tudo marcados pelo deslocamento da centralidade do debate jurídico do Estado para a pessoa humana!

Abstract: The study addresses the contours of the concept of public interest in the constitutional state of law, under the framework of the theory of neo, with the criticism of the traditional contours of the principle of the supremacy of the public interest over the private. The state constitutional right, seated on the theory of fundamental rights and the centrality of the principle of human dignity, calls for a profound redefinition of the contours of the legal administrative system, requiring the construction of a concept of the public interest consistent with this new engineering constitu-

Jürgen. Direito e democracia: entre facticidade e validade. Vol. I e II. Tradução de Flávio Beno Siebeneichler. Rio de janeiro: Tempo Brasileiro, 1997; HABERMAS, Jürgen. Teoría de la acción comunicativa. Traducción de Manuel Jiménes Redondo. Madrid: Taurus, 1987.

29 Para um estudo mais aprofundado acerca do princípio republicano, pode-se consultar: ATALIBA, Geraldo. República e constituição. 2. ed. atualizada por Rosolea Miranda folgosi. São Paulo: Malheiros, 1998. 
tional indelibly marked by the trace of humanist customization of normative constitutional. This new legal framework and political-institutional indicates overcoming the traditional centrality of the principle of the supremacy of the public interest over private, touted as a structuring principle of legal administrative system, with its normative readjustment to new vectors of the constitutional state of law, founded on fundamental rights and the primacy of human dignity.

Keywords: Public interest. State constitutional law. Principle of the supremacy of the public interest. Legal administrative system. dignity of the human person.

\section{REFERÊNCIAS}

ALEXY, Robert. Teoria de los derechos fundamentales. Madrid: Centro de Estudios Constitucionales, 1993.

ANDRADE, José Carlos Vieira de. Os direitos fundamentais na Constituição portuguesa de 1976. 5. ed. Coimbra: Almedina, 2012.

ATIENZA, Manuel. Entrevista a Robert Alexy. Cuadernos de Filosofía del Derecho, n. 24, Doxa, 2001, p. 671-687.

ÁVILA, Humberto. Teoria dos princípios: da definição à aplicação dos princípios jurídicos. 4. ed. São Paulo: Malheiros, 2004.

BANDEIRA DE MELLO, Celso Antônio. Curso de Direito Administrativo. 19. ed. São Paulo: Malheiros, 2005.

. Discricionariedade e controle jurisdicional. 2. ed. 3. Tir. São Paulo: Malheiros, 1998.

BARROSO, Luís Roberto. A constitucionalização do direito e suas repercussões no âmbito administrativo. In: ARAGÃO, Alexandre dos Santos; MARQUES NETO, Floriano de Azevedo (Coord.). Direito Administrativo e seus novos paradigmas. Belo Horizonte: Fórum, 2008, p. 31-63.

- Neoconstitucionalismo e constitucionalização do direito: o triunfo tardio do Direito Constitucional no Brasil. Boletim da Faculdade de Direito da Universidade de Coimbra, v. LXXXI, 2005, p. 233-289. 
BINENBOJM, Gustavo. Uma teoria do Direito Administrativo: direitos fundamentais, democracia e constitucionalização. 2. ed. São Paulo: Renovar, 2008.

BONAVIDES, Paulo. Curso de Direito Constitucional. 10. ed. São Paulo: Malheiros, 2000.

. Do Estado liberal ao Estado social. 6. ed. rev. e ampl. São Paulo: Malheiros, 1996.

CADEMARTORI, Sérgio. Estado de direito e legitimidade: uma abordagem garantista. 2. ed. Campinas (SP): Millennium, 2007.

CALSAMIGLIA, Albert. Postpositivismo. Cuadernos de Filosofía del Derecho, n. 21-I, Doxa, 1998, p. 209-220.

CANARIS, Claus-Wilhelm. Pensamento sistemático e conceito de sistema na ciência do Direito. Tradução de António Menezes Cordeiro. 2. ed. Lisboa: Fundação Calouste Gulbenkian, 1996.

CARBONELL, Miguel (Coord.). Neoconstitucionalismo(s). 2. ed. Madrid: Trotta, 2005.

. Teoría del neoconstitucionalismo: ensaios escogidos. Madrid: trotta, 2007.

CARBONELL, Miguel; SALAZAR, Pedro (Coord.). Garantismo: estudios sobre el pensamiento jurídico de Luigi Ferrajoli. Madrid: Trotta, 2005.

COSTA, Regina Helena. Conceitos jurídicos indeterminados e

discricionariedade administrativa. Revista de Direito Público, Ano 23, n. 95, Jul./Set., São Paulo: Revista dos Tribunais, 1990.

CRISTÓVAM, José Sérgio da Silva. A evolução do princípio de legalidade e o controle jurisdicional da discricionariedade administrativa. Revista Discente Interinstitucional (RDI), ano I, n. 1, jan./jun., Florianópolis: Fundação Boiteux, 2006.

- Colisões entre princípios constitucionais: razoabilidade, proporcionalidade e argumentação jurídica. 1. ed. 4. tir. Curitiba: Juruá, 2011.

. Direitos sociais e controle jurisdicional de políticas públicas: uma abordagem a partir dos contornos do Estado constitucional de direito. In: GAVAZZONI, Antônio Marcos; MARCELLINO JR., Julio Cesar (Org.). Constituição, Estado e Garantismo Jurídico: diálogos cruzados. 1 ed. São Paulo: Conceito Editorial, 2011, p. 11-35.

DALLARI, Dalmo de Abreu. Interesse público na contratação das entidades da administração descentralizada. Suplemento Jurídico da Procuradoria Jurídica do Departamento de Estradas e Rodagem. v. 126, jan./mar., São Paulo, 1987. 
DI PIETRO, Maria Sylvia Zanella. Direito Administrativo. 19. ed. São Paulo: Atlas, 2006.

- Da constitucionalização do Direito Administrativo: reflexos sobre o princípio da legalidade e a discricionariedade administrativa. In: DI PIETRO, Maria Sylvia Zanella; RIBEIRO, Carlos Vinícius Alves (Coord.). Supremacia do interesse público e outros temas relevantes do Direito Administrativo. São Paulo: Atlas, 2010, p. 175-196.

. O princípio da supremacia do interesse público: sobrevivência diante dos ideais do neoliberalismo. In: DI PIETRO, Maria Sylvia Zanella; RIBEIRO, Carlos Vinícius Alves (Coord.). Supremacia do interesse público e outros temas relevantes do Direito Administrativo. São Paulo: Atlas, 2010, p. 85-102.

DURÁN MARTÍNEZ, Augusto. Derechos prestacionales e interés público. In: BACELLAR FILHO, Romeu Felipe; HACHEM, Daniel Wunder (Coord.). Direito Administrativo e interesse público: estudos em homenagem ao Professor Celso Antônio Bandeira de Mello. Belo Horizonte: Fórum, 2010, p. 141-152.

ESPÍNDOLA, Ruy Samuel. Conceito de princípios constitucionais: elementos teóricos para uma formulação dogmática constitucionalmente adequada. 2. ed. São Paulo: Revista dos Tribunais, 2002.

FALDINI, Cristiana Corrêa Conde. A constitucionalização do Direito Administrativo. In: DI PIETRO, Maria Sylvia Zanella; RIBEIRO, Carlos Vinícius Alves (Coord.). Supremacia do interesse público e outros temas relevantes do Direito Administrativo. São Paulo: Atlas, 2010, p. 261-277.

FARIA, José Eduardo. Antinomias jurídicas e gestão econômica. Lua Nova: Revista de Cultura e Política, n. 25, Abril, 1992, p. 167-184.

FERRAJOLI, Luigi. Garantismo: una discusión sobre derecho y democracia. Madrid: Trotta, 2006.

2000 .

. Derecho y razón: teoría del garantismo penal. 4. ed. Madrid: Trotta,

FERRAZ JÚNIOR, Tércio Sampaio. Conceito de sistema no Direito. São Paulo: Revista dos Tribunais, 1976.

Interesse público. Revista do Ministério Público do Trabalho da $2^{a}$ Região, n. 01, Centro de Estudos, 1995.

GABARDO, Emerson; HACHEM, Daniel Wunder. O suposto caráter autoritário da supremacia do interesse público e das origens do Direito Administrativo: uma crítica da crítica. In: BACELLAR FILHO, Romeu 
Felipe; HACHEM, Daniel Wunder (Coord.). Direito Administrativo e interesse público: estudos em homenagem ao Professor Celso Antônio Bandeira de Mello. Belo Horizonte: Fórum, 2010, p. 155-201.

HABERMAS, Jürgen. Direito e democracia: entre facticidade e validade. Tradução de Flávio Beno Siebeneichler, vol. II. Rio de Janeiro: Tempo Brasileiro, 1997.

. Um ensaio sobre a Constituição da Europa. Coimbra: Almedina, 2012.

JUSTEN FILHO, Marçal. Curso de Direito Administrativo. São Paulo: Saraiva, 2005.

LUCAS VERDÚ, Pablo. Estado liberal de derecho y Estado social de derecho. Madrid: Universidad de Salamanca, 1955.

MEILÁN GIL, José Luis. Intereses generales e interés público desde la perspectiva del Derecho Público español. In: BACELLAR FILHO, Romeu Felipe; HACHEM, Daniel Wunder (Coord.). Direito Administrativo e interesse público: estudos em homenagem ao Professor Celso Antônio Bandeira de Mello. Belo Horizonte: Fórum, 2010, p. 65-88.

MIRANDA, Jorge. A dignidade da pessoa humana e a unidade valorativa do sistema de direitos fundamentais. In: MIRANDA, Jorge (Org.). Estudos em homenagem ao Prof. Doutor Martim de Albuquerque. vol. I. Coimbra: Coimbra Editora, 2010, p. 933-949.

MIRANDA, Jorge; SILVA, Marco Antonio Marques da (Coord.). Tratado luso-brasileiro de dignidade humana. São Paulo: Quartier Latin, 2008.

MUÑOZ, Guillermo Andrés. El interés público es como el amor. In: BACELLAR FILHO, Romeu Felipe; HACHEM, Daniel Wunder (Coord.). Direito Administrativo e interesse público: estudos em homenagem ao Professor Celso Antônio Bandeira de Mello. Belo Horizonte: Fórum, 2010, p. 21-31.

OSÓRIO, Fábio Medina. Existe uma supremacia do interesse público sobre o privado no Direito Administrativo brasileiro? Revista de Direito Administrativo, n. 220, 2000, p. 69-107.

OTERO, Paulo. Legalidade e Administração Pública: o sentido da vinculação administrativa à juridicidade. Coimbra: Almedina, 2007.

PEREZ LUNÕ, Antonio Enrique. Derechos humanos, Estado de derecho y Constituición. 5. ed. Madrid: Tecnos, 1994.

PISARELLO, Geraldo. Del Estado social legislativo al Estado social constitucional: por una protección compleja de los derechos sociales. Revista de Teoría y Filosofía del Derecho, n. 15, Isonomía, 2001, p. 81-107. 
RODRÍGUEZ-ARANA MUÑOZ, Jaime. El interés general como categoría central de la actuación de las Administraciones Públicas. In: BACELLAR FILHO, Romeu Felipe; HACHEM, Daniel Wunder (Coord.). Direito Administrativo e interesse público: estudos em homenagem ao Professor Celso Antônio Bandeira de Mello. Belo Horizonte: Fórum, 2010, p. 33-63.

SARLET, Ingo Wolfgang. A eficácia dos direitos fundamentais. 9. ed. Porto Alegre: Livraria do Advogado, 2007.

- Dignidade da pessoa humana e direitos fundamentais na Constituição Federal de 1988. 3. ed. Porto Alegre: Livraria do Advogado, 2004.

SARLET, Ingo Wolfgang; TIMM, Luciano Benetti (Org.). Direitos fundamentais, orçamento e reserva do possível. 2. ed. Porto Alegre: Livraria do Advogado, 2010.

SARMENTO, Daniel (Org.). Interesses públicos versus interesses privados: desconstruindo o princípio da supremacia do interesse público. Rio de Janeiro: Lúmen Júris, 2005.

. O neoconstitucionalismo no Brasil: riscos e possibilidades.

In: LEITE, George Salomão; SARLET, Ingo Wolfgang (Org.). Direitos fundamentais e Estado Constitucional: estudos em homenagem a J. J. Gomes Canotilho. São Paulo; Coimbra: Revista dos Tribunais; Coimbra Editora, 2009, p. 09-49.

SILVA, Vasco Pereira da. O contencioso administrativo no divã da psicanálise: ensaio sobre as acções no novo processo administrativo. 2. ed. Coimbra: Almedina, 2009.

STRECK, Lenio Luiz. Ministros do STJ não devem se aborrecer com a lei. Disponível em: <http://www.conjur.com.br/2012-jun-07/senso-incomumnao-aborreca-lei-ministra-nancy-andrighi >. Acesso em: 09 de jun. 2012.

VEDEL, Georges. Derecho Administrativo. Traducción de la 6a edición francesa por Juan Rincón Jurado. Madrid: Biblioteca Jurídica Aguilar, 1980.

VIEHWEG, Theodor. Tópica y jurisprudencia. Traducción de Luis DíezPicazo Ponce de Leon. Madrid: Taurus, 1964.

TORRES, Ricardo Lobo. A Constituição de 1988 e a teoria dos direitos fundamentais. In: VIEIRA, José Ribas (Org.). 20 anos da Constituição cidadã: efetivação ou impasse institucional? Rio de Janeiro: Forense, 2008, p. 271-290. 